\title{
Effect of magnetic field on performance and emission of single cylinder four stroke diesel engine
}

\author{
Piyush M Patel $^{1}$, Prof. Gaurav P Rathod ${ }^{2}$,Prof. Tushar M Patel ${ }^{3}$ \\ ${ }^{1}$ (ME Scholar,Department of Mechanical Engineering / KSV University, Gujarat,India) \\ ${ }^{2}$ (Assistant Proffesor,Department of Mechanical Engineering / KSV University, Gujarat,India) \\ ${ }_{3}^{3}$ (Associate Proffesor Department of Mechanical Engineering / KSV University, Gujarat,India)
}

\begin{abstract}
To analyse experimental investigates on the Performance and Emission of Single Cylinder Four Stroke Diesel engine under the power of producingan effect of magnetic field. The magnetic field applied along the fuel line immediately before fuel injector. It has been reported that magnetic field helps to improved mixture formation by increasing the atomization process of the spray in the combustion chamber due to increasing the rate of disintegration of the droplets as a result of reduction in the surface tension and viscosity of the fuel[1]. The effect of magnetic field on the engine performance parameters such as specific fuel consumption, break thermal efficiency, exhausts emissions etc. by applying the magnetic field along the fuel line immediately before fuel injector. The strong permanent magnet of strength 2000 gauss is applied to fuel line for magnetic field. At different engine load conditions the experiments are conducted. An exhaust gas analyzer is used to measure the exhaust gas emissions such as $\mathrm{CO}, \mathrm{CO}_{2}, \mathrm{HC}$ and $\mathrm{NO}_{\mathrm{x}}$. With the application of magnetic field the percentage reduction in fuel consumption is about $8 \%$ at higher load, the percentage reduction in $\mathrm{HC}$ and $\mathrm{NO}_{\mathrm{x}}$ is about $30 \%$ and $27.7 \%$ respectively. The $\mathrm{CO}$ emission gets reduced with the application of magnetic field at higher load. The percentage reduction in $\mathrm{CO}_{2}$ emissions is reduced about $9.72 \%$ at average of all loads with the effect of magnetic field.
\end{abstract}

Keywords: - Efficiency, Emission, Exhaust gas analyzer, Magnetic Fuel Energizer.

\section{INTRODUCTION}

In recent years, there are so many efforts towords the improving power output and emission of internal combustion engines per fuel, so that the products of combustion exhausted from internal combustion (IC) engines environmental friendly, and also beneficial for cost. The use of diesel engines have been increase day by day, due to their high thermal efficiency and low pollutant formation characteristics but it has a serious drawback of having a comparative larger amount of emission which is larger than that of a gasoline engine.

Magnetic field that ionized the fuel based on the principle of magnetic field mutual action with hydrocarbon molecules of fuel and oxygen molecules. There are various physical attraction forces between hydrocarbons and they form densely packed structures called pseudo compounds which can further organize into clusters [8]. Due to the physical attraction forces between hydrocarbons, oxygen atoms cannot penetrate into their interior during air/fuel mixing process, these structures become stable. The external force by means of magnetic field helps to polarized the hydrocarbon fuel. Due to that hydrocarbon fuel change their orientation and increase space between hydrogen. This hydrogen of fuel actively interlocks with oxygen and producing a more complete burn in the combustion chamber[6] It has been noted that When the fuel passes through a magnetic field, it helps increasing the atomization process by improved mixture formation. Due to increasing the rate of disintegration of the droplets as a result of reduction in the surface tension and viscosity of the fuel[7].

\section{MAGNETIC FUEL ENERGIZER}

Hydrogen occurs in two distinct isomeric forms one is Para which is normally occurs in fuels, second is ortho which achieved by applying magnetic field. These two forms are characterized by the different opposite nucleus spins. The ortho state can be achieved by applying strong magnetic field along the fuel line [2]. In the para Hydrogen molecule, which occupies the anti-parallel rotation, the spin state of one atom relative to another is in the opposite direction, therefore it is diamagnetic. In the ortho molecule, which occupies the parallel rotational levels, the spin state of one atom relative to another is in the same direction as shown in Figure.1, therefore, it is paramagnetic [3]. 


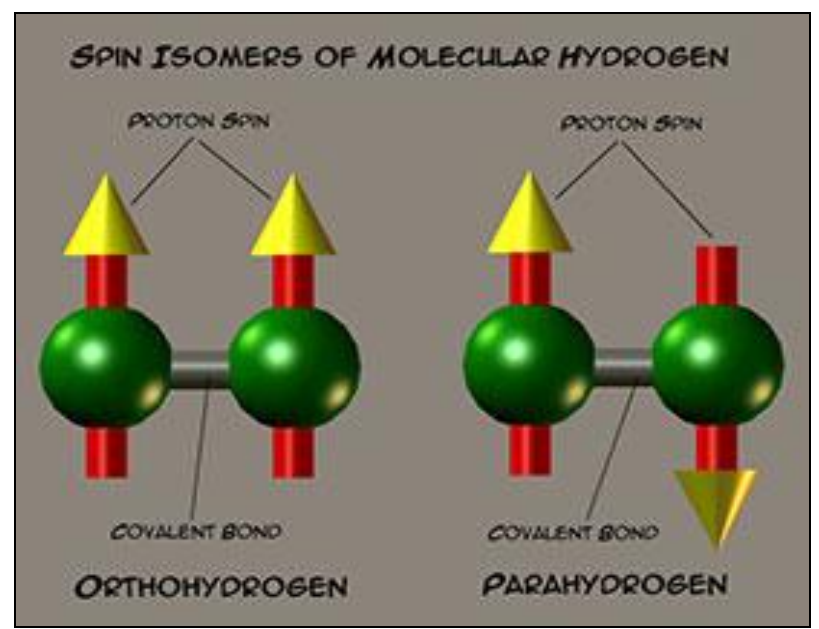

Fig.1 Schematic view of Spin isomers of molecular Para and Ortho state of Hydrogen[9]

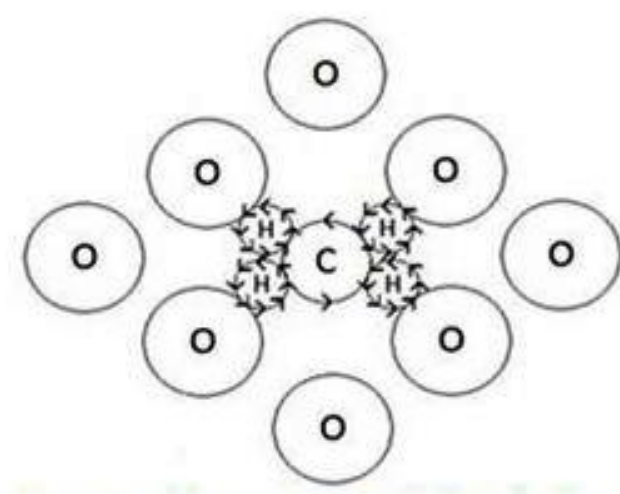

Para-Hydrogen at Time of Combustion

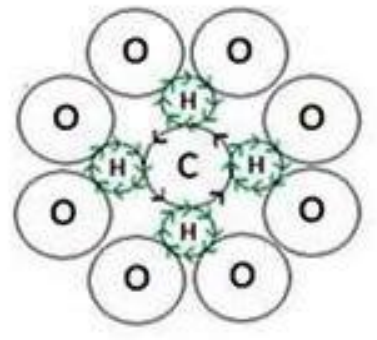

Ortho-Hydrogen at Time of Combustion

Fig.2 Schematic view of (a) Para state of Hydrogen and (b) Ortho state of Hydrogen[9]

When the fuel passes through a magnetic field, created by the strong permanent magnets, due to that magnetic field hydrocarbon change their orientation and convert from para state to ortho state[5]. In ortho state inter molecular force is considerably reduced and increase space between hydrogen. This hydrogen of fuel actively interlocks with oxygen and producing a more complete burn in the combustion chamber[4]. The magnetic field helps to disperse oil particles and to become finely divided.Figure. 2 shows the schematic view of para state and ortho state of Hydrogen of clusters of hydrocarbons changed with the influence of magnetic field and they are more dispersed.

\section{EXPERIMENTAL SET UP AND PROCEDURE}

The performance tests were carried out on a single cylinder, four stroke water cooled Diesel engine. The setup consists of an engine, an eddy current dynamometer, and an exhaust gas analyzer.

Technical Specifications

\begin{tabular}{|l|l|}
\hline Model & TV1 \\
\hline Make & Kirlosker Oil Engines \\
\hline Type & Four stroke, Water cooled, Diesel \\
\hline No. of cylinder & One \\
\hline Bore & $87.5 \mathrm{~mm}$ \\
\hline Stroke & $110 \mathrm{~mm}$ \\
\hline Combustion principle & Compression ignition \\
\hline Cubic capacity & 0.661 liters \\
\hline Compression ratio 3 port & $17.5: 1$ \\
\hline Lubrication system & Forced feed system \\
\hline
\end{tabular}




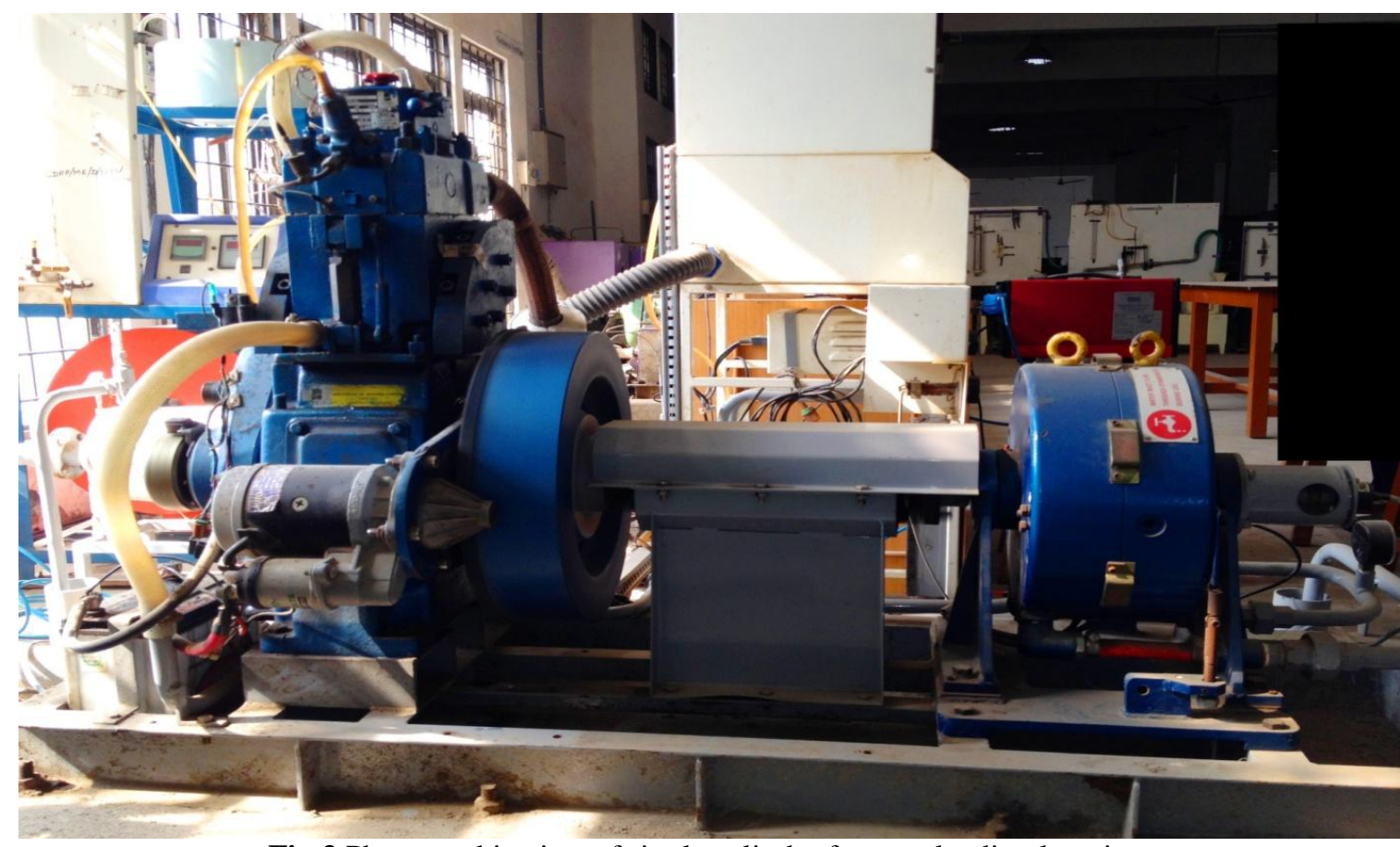

Fig.3 Photographic view of single cylinder four stroke diesel engine

The engine was prepared to run on diesel as a fuel during all tests. The fuel system is designed to facilitate for accurate measurement of the fuel flow rate. The fuel consumption is measured directly by using the burette method. The fuel consumption was measured at different engine loading conditions and exhaust gas measured by Exhaust gas analyzer. The exhaust gas analyzer is used to measure exhaust emissions from the engine during experimental tests. It is measures gases such as $\mathrm{HC}, \mathrm{CO}, \mathrm{NO}_{\mathrm{X}}$ and $\mathrm{CO}_{2}$ concentrations at each and every load. This procedure was done twice one for without magnet situation and other for with magnet situation, and results were compared.

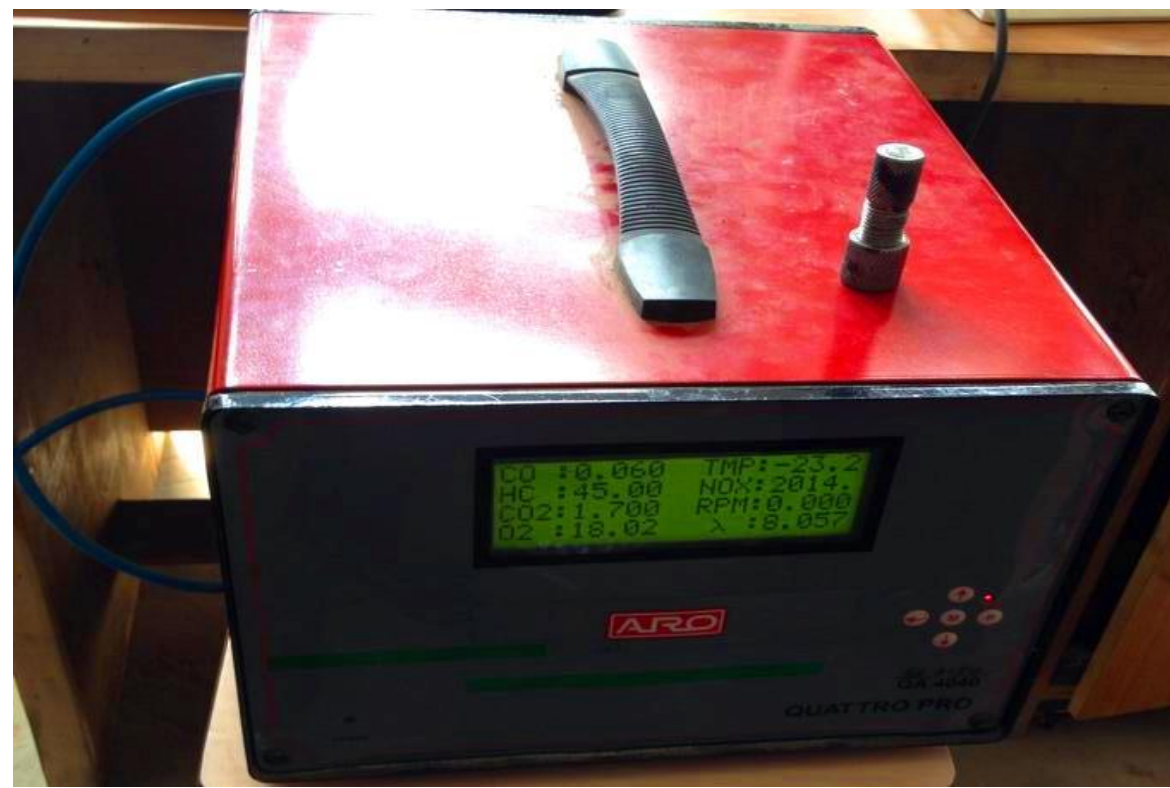

Fig.4. Photographic view of exhaust gas analyzer

\section{Properties of Magnet}

Ferrite magnet is the compound of ceramic and Iron oxide. This is an example of permanent magnet and used as ferrite cores in the transformer. Generally, ferrite magnets are carbon black in colour as shown in Figure. 5 and brittle because the present of ceramic particle in the chemical compound. Ferrite magnets also considered as strong magnets but not as strong as neodymium magnets 


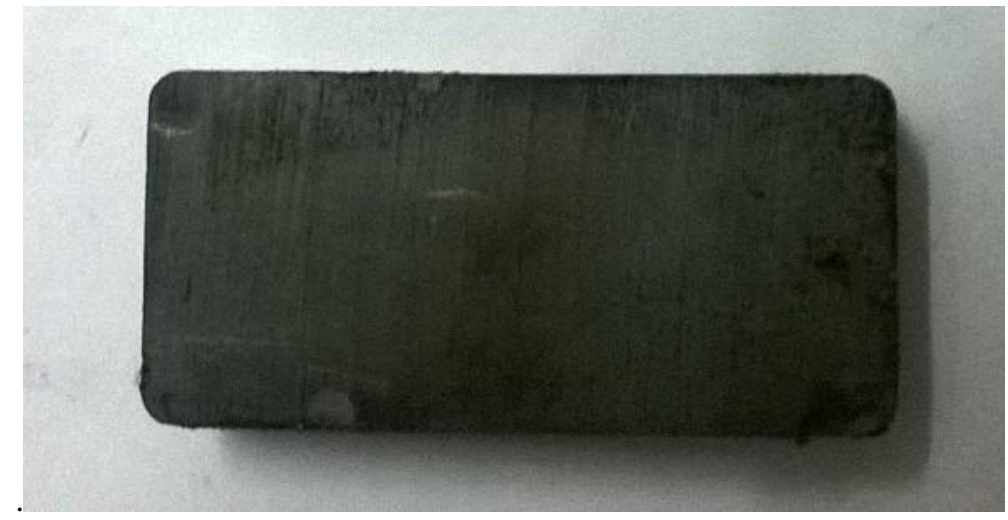

Fig.5 Photographic view of Ferrite Magnets

Installation Position: It is just before the injector on inlet pipe or housing for maximum alignment \& maximum effect.

\section{RESULTS AND DISCUSSION}

Magnetic field effect on Specific fuel consumption

The experimental results show that the fuel consumption of engine was less when the engine with magnet than that without fuel magnet at higher load. Always less amount of fuel was consumed with the fuel with magnetic field. The SFC vs LOAD graph is as shown in fig.6

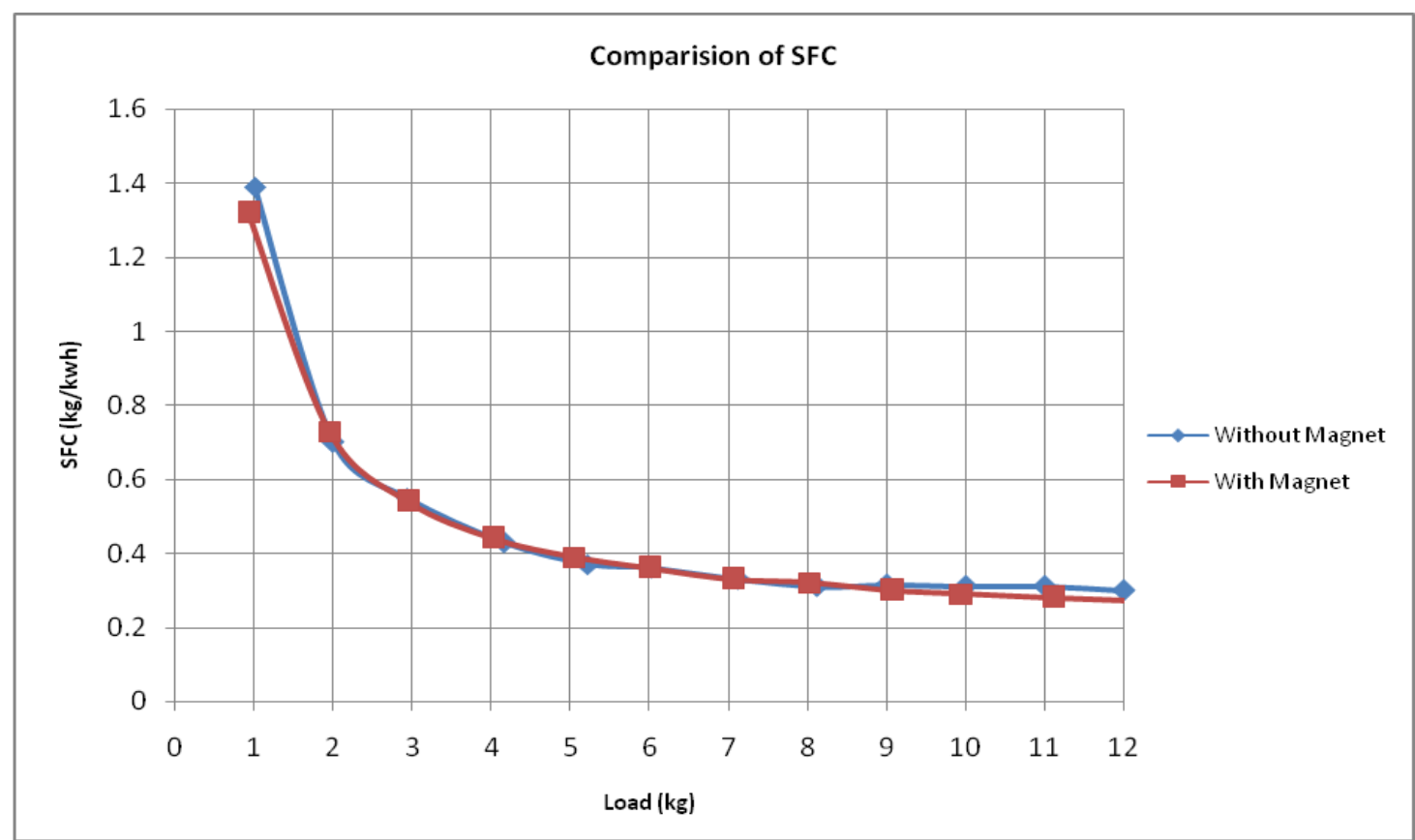

Fig.6 Variation of Specific fuel consumption with load

\section{Magnetic field effect on Brake Thermal Efficiency}

The experimental results show that the Brake Thermal Efficiency of engine was less when the engine with magnet than that without fuel magnet at higher load. 


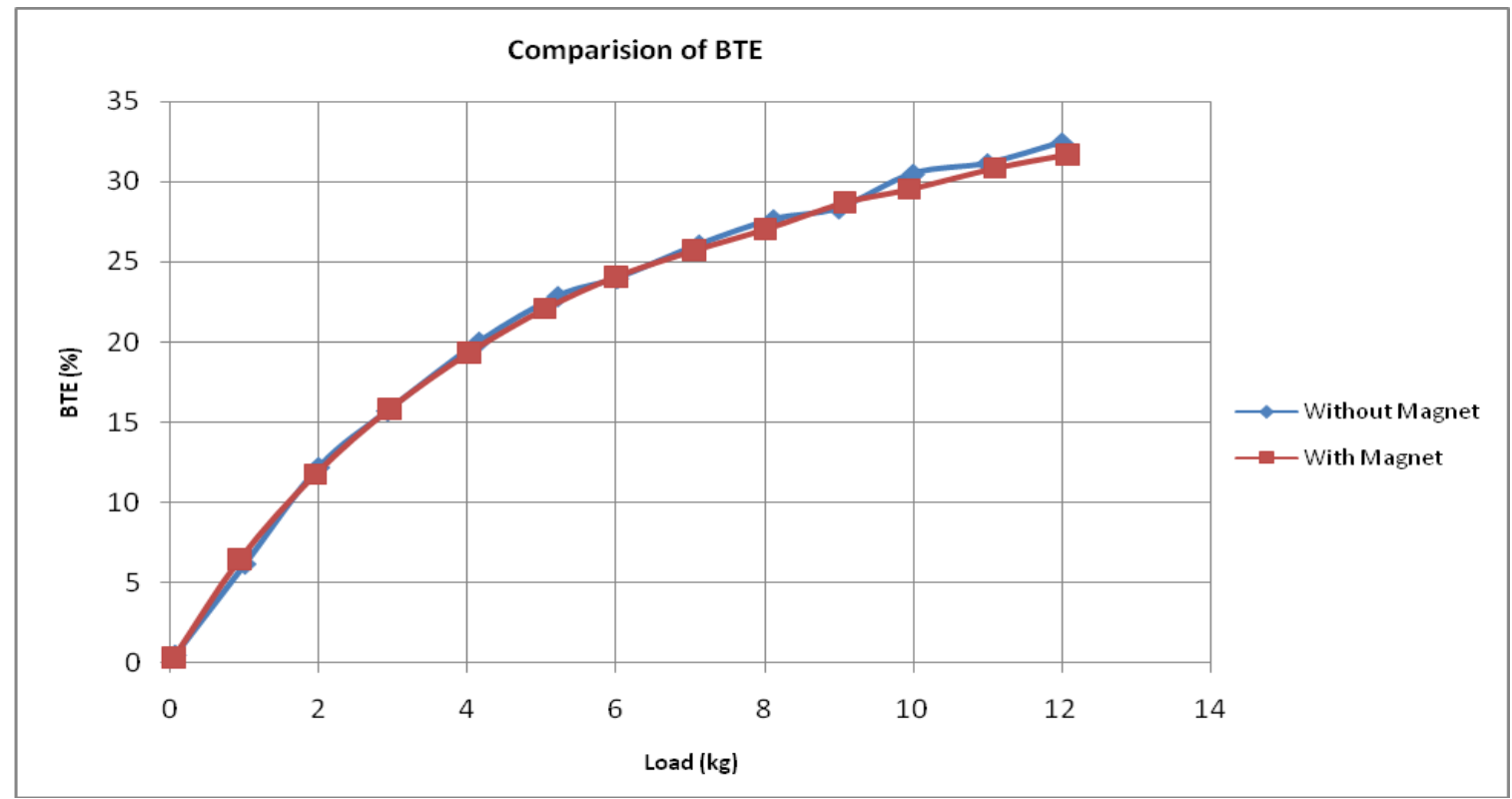

Fig.7 Variation of Brake Thermal Efficiency with load

The variation of Brake power Vs brake thermal efficiency is as shown in fig.7. It is clear that with the application of magnetic field the brake thermal efficiency goes on increasing. The percentage increase of brake thermal efficiency is about up to $2 \%$.

\section{Magnetic field effect on Nox emissions}

The NOx emission gets decrease with the application of magnetic field as compared to the $\mathrm{NO}_{\mathrm{X}}$ without magnetic field. Here the magnetic field shows adverse effect. The NOx emissions are decrease around $27.7 \%$ at average of all loads. The variation of NOx emissions with load is as shown in fig. 8

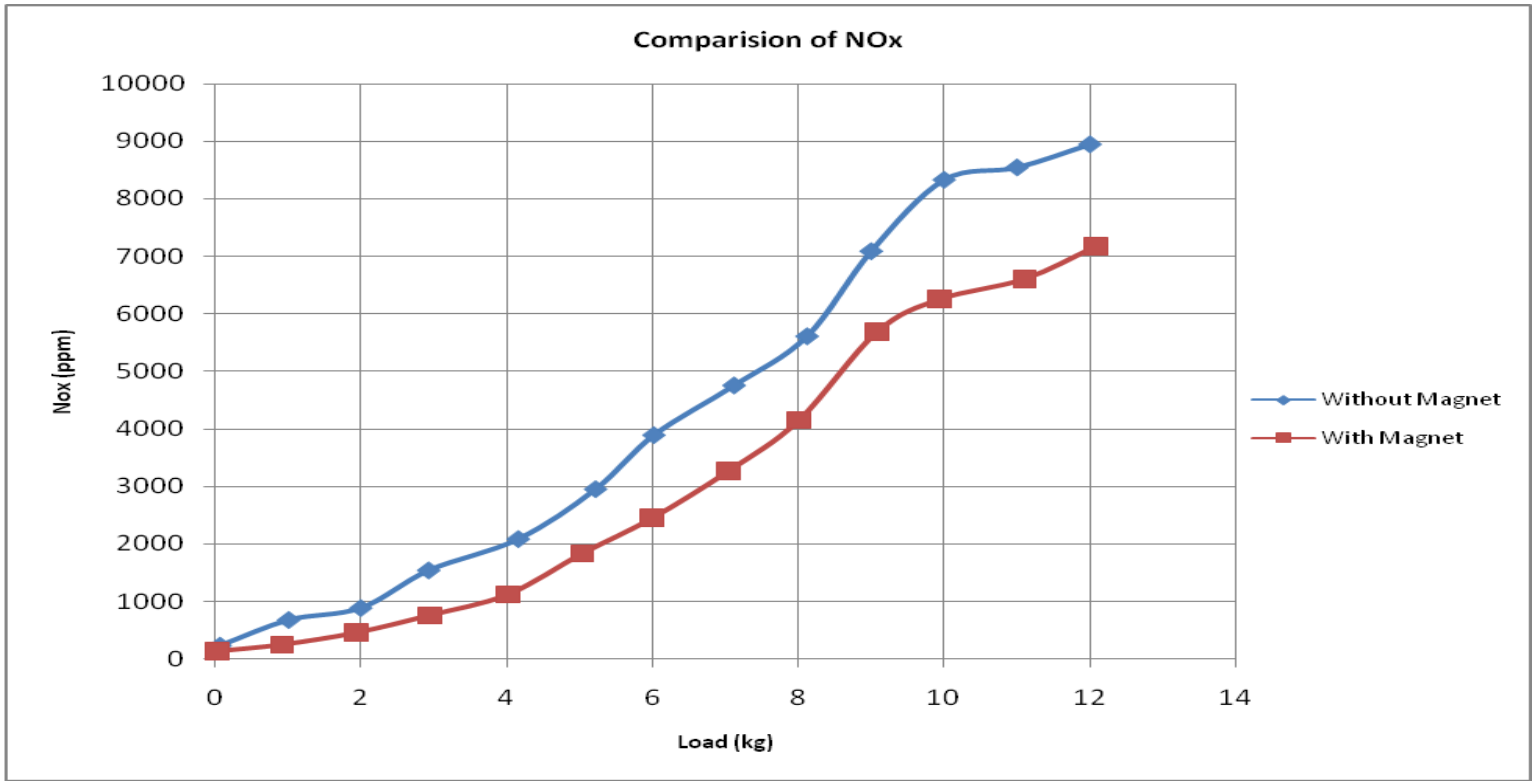

Fig.8 Variation of NOx(ppm) with load

\section{Magnetic field effect on $\mathrm{HC}$ emissions}

Fig.9. Clearly shows the effect of magnetic field on $\mathrm{HC}$ emissions, and the percentage reduction of HC. The $\mathrm{HC}$ emissions are decrease around 30\% at average of all loads. The variation of $\mathrm{HC}$ emissions with load is as shown in fig. 9 


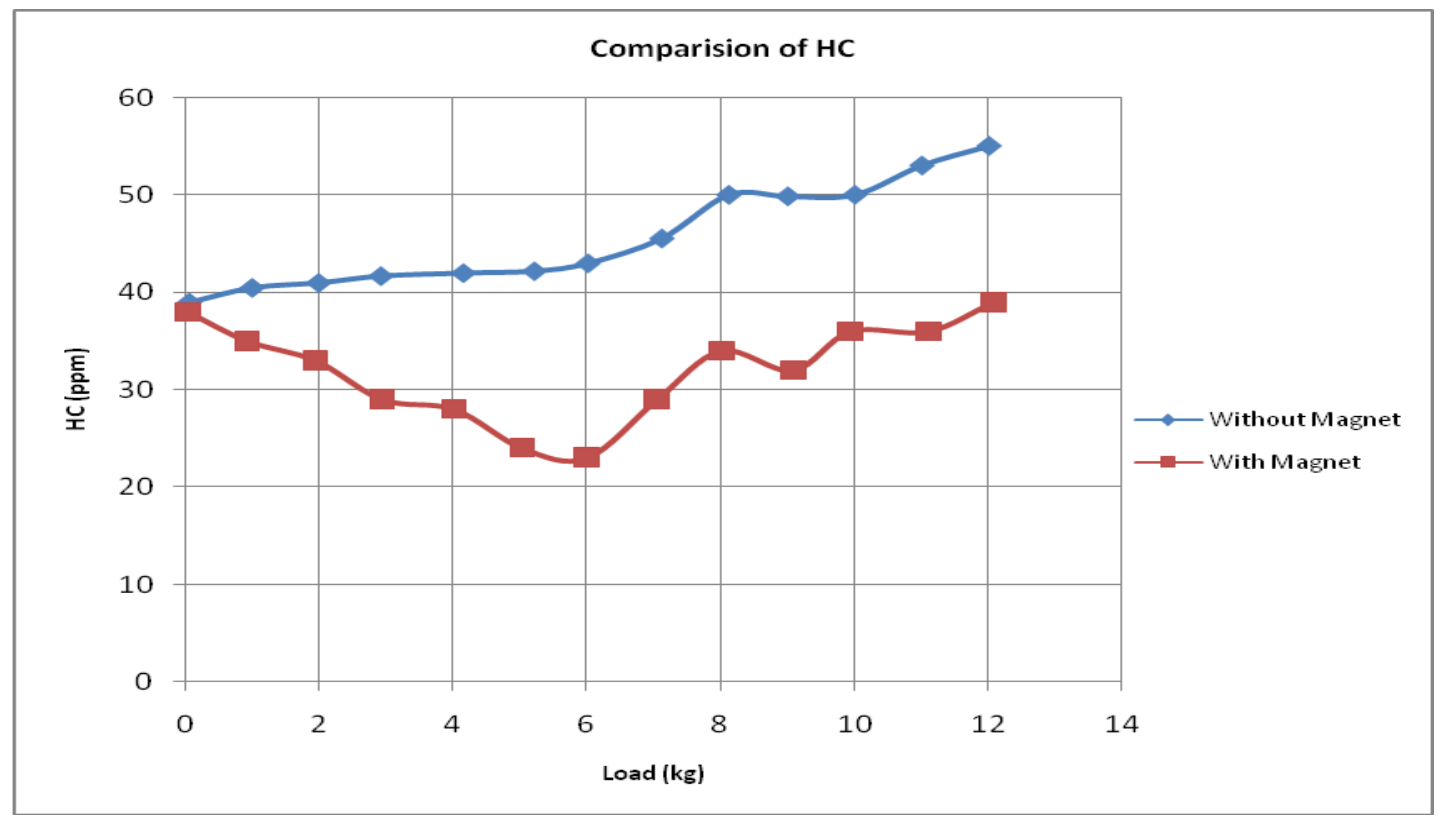

Fig.9 Variation of HC(ppm) with load

\section{Magnetic field effect on CO emissions}

With the application of magnetic field $\mathrm{CO}$ emissions gets reduced as compared to the $\mathrm{CO}$ emissions without magnetic field. Fig.10. Clearly shows the effect of magnetic field on $\mathrm{CO}$ emissions and the $\mathrm{CO}$ emission reduces at higher load.

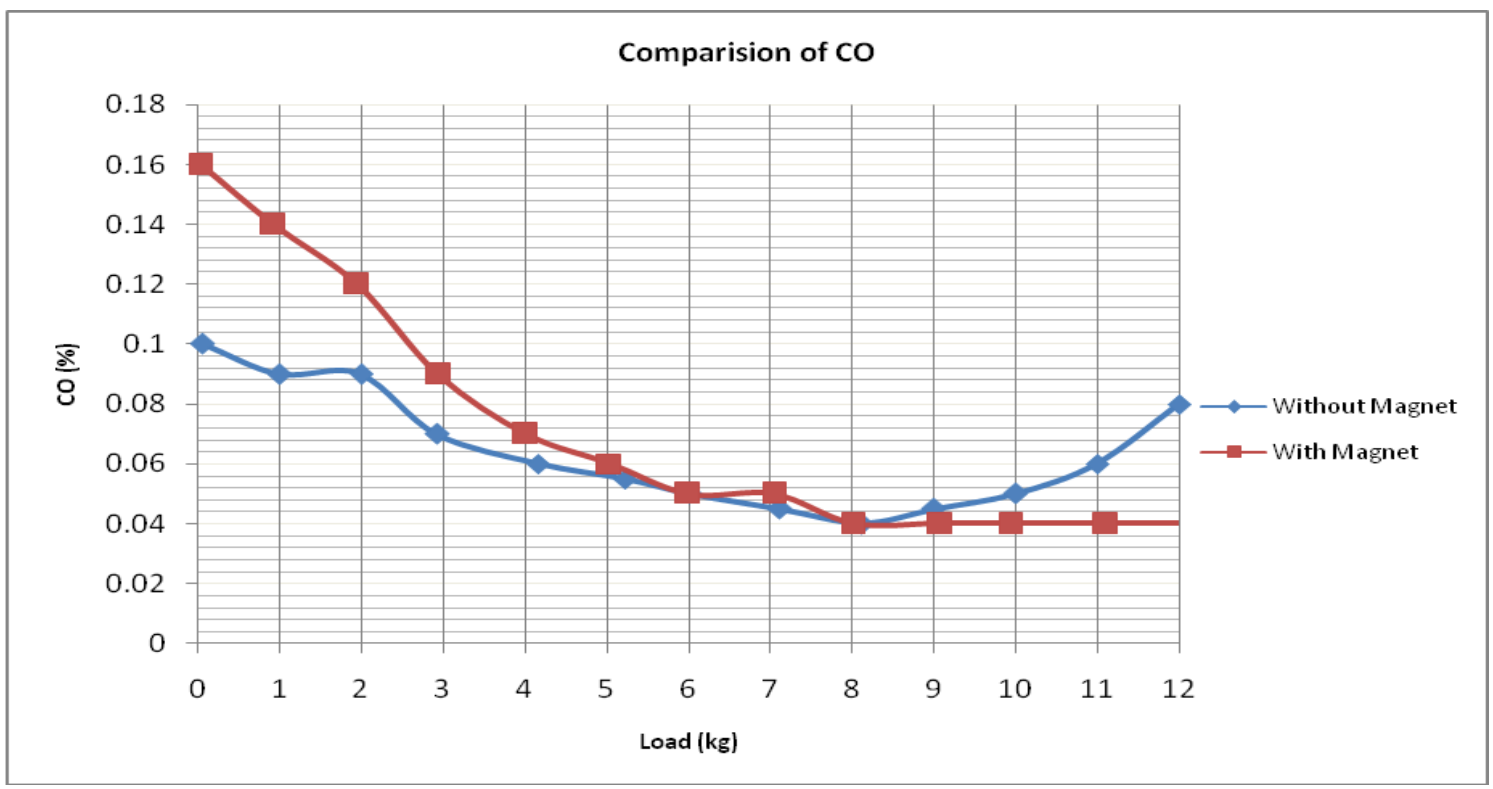

Fig.10 Variation of $\mathrm{CO}$ with load

\section{Magnetic field effect on $\mathrm{CO}_{2}$ emissions}

The $\mathrm{CO}_{2}$ emission gets decrease with the application of magnetic field as compared to the $\mathrm{CO}_{2}$ without magnetic field. Here the magnetic field shows adverse effect. The $\mathrm{CO}_{2}$ emissions are decrease around $9.72 \%$ at average of all loads. The variation of $\mathrm{CO}_{2}$ emissions with load is as shown in fig. 11 


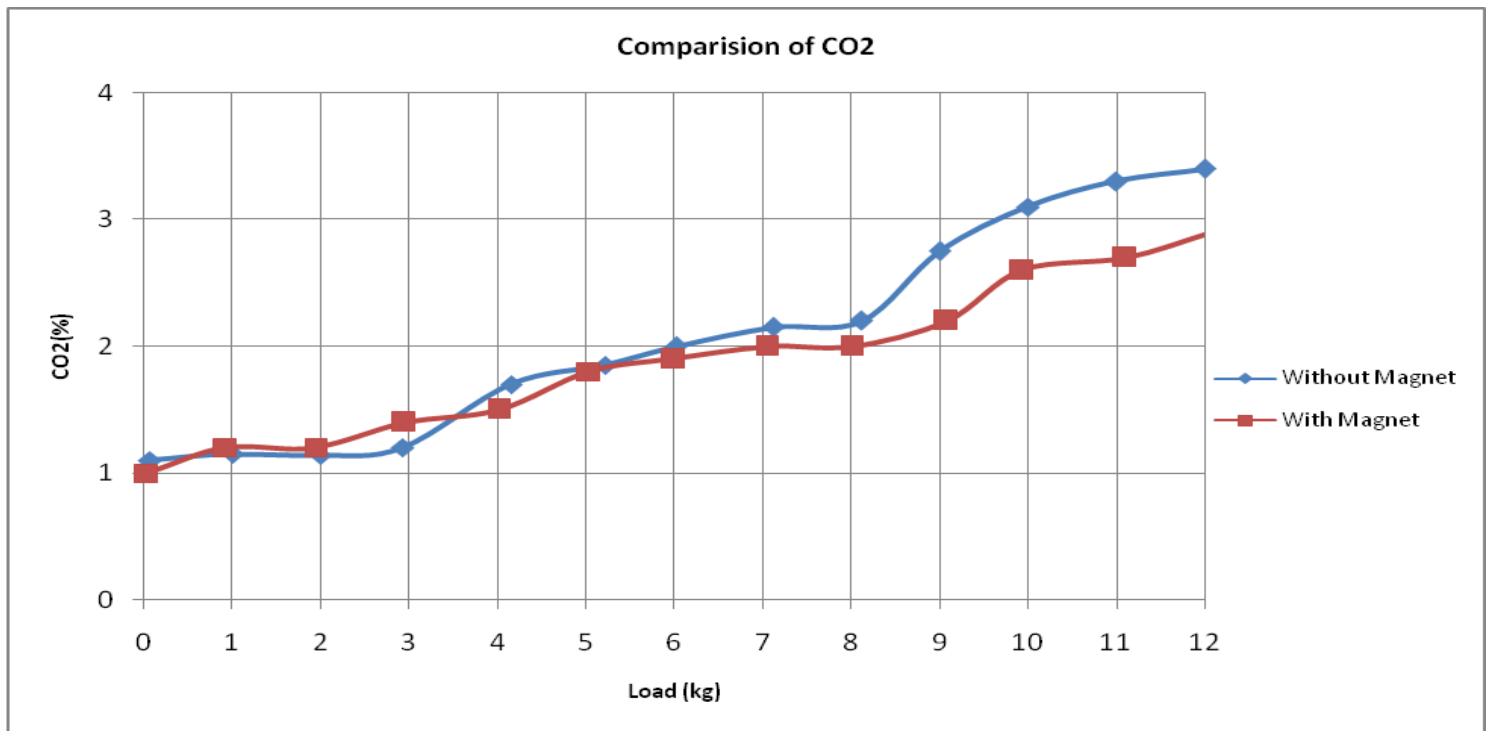

Fig.11 Variation of $\mathrm{CO}_{2}$ with load

\section{CONCLUSION}

From the above experimental results the following conclusions were made:

It is clear from the experiment result that the brake thermal efficiency, indicated power are similar in both with and without Magnet Fuel Energizer but indicated power gets improve at lower load condition. Specific fuel consumption decreases due to the reduction of fuel consumption at higher load.

There is significant reduction in the exhaust emissions at all load condition in both neodium and ferrite but among them two neodium gave better effect than the ferrite. The experiments results show the magnetic effect on fuel consumption reduction was up to $8 \%$ at higher load condition. The $\mathrm{CO}$ emission gets reduce at higher load. The effect on NOx emissions reduces range up to $27.7 \%$. The reduction of $\mathrm{HC}$ emissions was range up to $30 \%$. The $\mathrm{CO}_{2}$ emission reduction was up to $9.72 \%$ at average of all loads.

\section{REFERENCES}

[1] Daniel C. Uguru-Okorie and Ademola A. Dare "Combustion Enhancers in Diesel Engines: Magnetic Field Option"IOSR Journal of Mechanical and Civil Engineering (IOSR-JMCE) e-ISSN: 2278-1684 Volume 5, Issue 5 (Mar. - Apr. 2013), PP 21-24

[2] P. Govindasamy and S. Dhandapani,"Experimental Investigation of Cyclic Variation of Combustion Parameters in Catalytically Activated and Magnetically Energized Two-stroke SI Engine”. Journal of scientific and industrial research vol.66, 2007;pp-457-463

[3] Farrag A.El Fatih, 2Gad M.saber, Effect of Fuel Magnetism on Engine Performance and Emissions, Australian Journal of Basic and Applied Sciences, 4(12): 6354-6358, 2010 ISSN 1991-8178

[4] Shweta Jain, Prof. Dr. Suhas Deshmukh,2012 Experimental Investigation of Magnetic Fuel Conditioner (M.F.C) in I.C. engine, ISSN: 2250-3021 Volume 2, Issue 7 (July 2012), PP 27-31

[5] Ali S. Faris, Saadi K. Al-Naseri, Nather Jamal, Raed Isse, Mezher Abed, Zainab Fouad, Akeel Kazim, Nihad Reheem, Ali Chaloob, Hazim Mohammad, Hayder Jasim, Jaafar Sadeq, Ali Salim, Aws Abas, "Effects of Magnetic Field on Fuel Consumption and Exhaust, Emissions in Two-Stroke Engine", Energy Procedia 18 ( 2012 ) 327 - 338 www.sciencedirect.com

[6] Vivek Ugare, Nikhil Bhave, Sandeep Lutade,2013 Performance of spark ignition engine under the influence of magnetic field, International journal of research in aeronautical and mechanical engineering ,vol.1 Issue. 3 July 2013 Pgs:36-43

[7] Ajaj R. Attar, Pralhad Tipole, Dr.Virendra Bhojwani, Dr.Suhas Deshmukh, "Effect of Magnetic Field Strength on Hydrocarbon Fuel Viscosity and Engine Performance", International Journal of Mechanical Engineering and Computer Applications, Vol 1, Issue 7,December 2013, ISSN 2320-6349

[8] H. Guo, Z. Liu, Y. Chen and R. Yao,"A Study of Magnetic effects on the Physicochemical Properties of Individual Hydrocarbons" Logistical Engineering College, Chongqing 400042, P.R China(1994), pp.216220

[9] Website: www.aferinc.com/afer-system.php 